\title{
THE BIO-POLITICS OF SOCIOBIOLOGY AND PHILOSOPHY
}

\author{
MICHAEL W. FOX \\ Humane Society of the United States
}

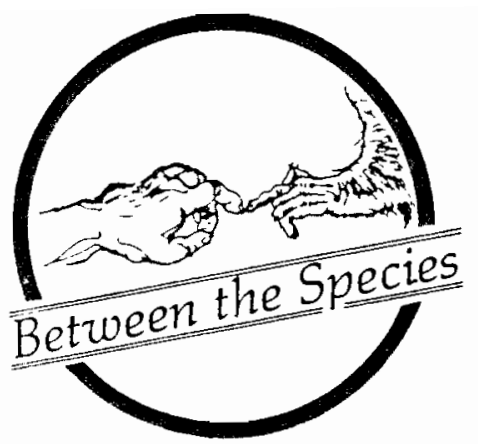

Dr. Wilson adds :

There are certain views being advanced by academicians that are relevant to how we, as a society, relate to and treat animals and Nature. As will be shown, these views give support to the bio-politics of animal and Nature exploitation and, therefore, should be challenged on ethical as well as scientific grounds.

One view that is being advanced is that humans are superior to other animals. Those who adhere to such a belief may then be incapable of ethically objective and responsible action toward animals, because they perceive animals as being inferior. With this preconceived notion that humans are superior (and that some animal species are more or less superior to others) the ethically objective principle of giving animals equal and fair consideration-which is a basic premise of animal rights philosophy--is anathema.

In apparent support of this view, Harvard University"sociobiologist" and science popularizer Edward $O$. Wilson has constructed a list of the ten most intelligent animals:

1. Chimpanzee (two species)

2. Gorilla

3. Orangutan

4. Baboon (seven species, including drill and mandrill)

5. Gibbon (seven species)

6. Monkey (many species, especially macaques, the patas, and the Celebes black ape)

7. Smaller toothed whale (several species, especially killer whale)

8. Dolphin (many of the approximately 80 species)

9. Elephant (two species)

10. Pig.
I defined intelligence as the speed and extent of learning performance over a wide range of tasks. Insofar as possible, the rank ordering was based in part on actual experiments conducted on learning ability. In those cases where such studies have not been made, I relied on the "encephalization index," which measures the size of the brain relative to that of the body as a whole and has been shown to be roughly correlated with intelligence. Although I believe that my rank ordering is relatively sound, much more research is needed in this field of zoology, and changes in position can easily occur, especially near the bottom of the list of 10.[1]

It should be pointed out, however, that "speed and extent of learning performance over a wide range of tasks" and the "encephalization index" are arbitrary, not absolute, indices of intelligence. Comparing the learning performance and brain size relative to that of the body of different species sets up absolute differences between species. And when a hierarchy is drawn up, a further erroneous inference is made, namely that of superiority.

This "speciesist thinking" is a reflection of our own values, especially of our valuing intelligence as some special virtue. Such valuation can distort our perceptions of

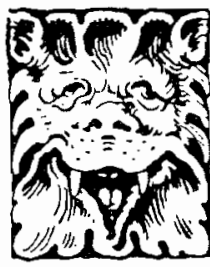


other animals and influence how we treat them and value them in and for themselves. A "dumb beast," low in the sapience or I.Q. hierarchy, would not be accorded the same respect as a more intelligent species (i.e., one "nore human" in some respect). Yet, all animals should be respected equally, since they are all sentient, having the capacity to feel and to suffer.

While comparing different species is one avenue to understanding evolution, adaptation, and the structure and function of living things, making comparisons on the basis of biased, human-centered values can have pernicious ramifications. Any hierarchy (of superior-inferior, greater-lesser) sets up a false view of reality, and when it is imposed upon the animal kingdom, it can break the circle of compassion within wich all creatures should be regarded and treated with equal reverence and respect.

That Professor Wilson listed the chimpanzee first and not Homo sapiens is his first biological error. But it is, I believe, a politically coercive, if not unconscious, onission. It would seen by this onission that Wilson would have us believe that we are so superior to all other animals that we do not rank with them. Yet, are we not, along with the gorilla and orangutan, less intelligently adapted to life in the water than a dolphin (which he ranks eighth)? And is not a tenth-ranking pig more intelligent at being a pig, and living in its own particular environmental niche, than a dolphin or a chimpanzee could ever be?

What is Professor Wilson doing? Other biologists before him placed Negro and European and Asian peasant races beneath their white, Anglo-Saxon, Protestant ideal of superiority and human perfection. With such an arrogant attitude of patriarchal supremacy over others and the rest of creation, no ethical decision could be objective and unbiased. All moral choices would be decided upon by some arbitrary consensus of reality and of our supreme place in Nature that would be ultimately self-serving. Wilson's animal I.Q. hierarchy sets up the pyramid of power. Is it not as "speciesist" as his predecessor bio-politicians were racist?

Then there is philosopher Mortimer $\mathrm{Ad}$ ler, whose books, like biologist Wilson's, present the speciesist view of human superi- ority over the animal kingdom as some irrefutable truth. His writings have wide public appeal and have been lauded by educators, though other philosophers generally ignore his pontifications.

In many of his writings, he has argued that rationality is the highest virtue and that since humans are the only truly rational beings on Earth, they are superior to the rest of creation, and, consequently, there is nothing morally wrong in exploiting animals.

In his most recent popular book, Ten Philosophical Mistakes, he supports the views of Thomas Aquinas, who derived his philosophy from Aristotle and incorporated it into Christian theology, reasoning, for example, that only rational beings (i.e.., humans) have imnortal souls. Animals are, therefore, inferior. So, naturally, Adler is critical of Charles Darwin (who was cognizant of animals' emotions and was concerned about their widespread mistreatment, especially by vivisectors) for classifying humans as animals. Professor Adler contends that humans alone can conceive of right and wrong. Thus, humans are a superior kind of being, capable of moral responsibility and ethical conduct. However, we, unlike animals, have the power of free-will to act immorally and unethically, so does this not make us "inferior" to other animals? That it is in our best interests to be morally right and ethically responsible is a sign of enlightened selfinterest, not of superiority over the animal kingdom. It is worth noting that Adler stresses the difference in sapience of humans over animals that makes us superior, rather than emphasizing (as did Darwin) the similarities in sentience--in emotional reactions and feelings--that make us feel kinship and compassion rather than superiority.

It should be emphasized that many opponents of animal rights philosophy have argued that only humans can have rights because only humans can act as moral agents. Non-rational animals having no sense of right or wrong, cannot, therefore, have rights. But since babies and comatose patients, who are neither rational nor capable of being moral agents, have rights because they are recognized as "moral abjects," it is illogical not to regard animals also as objects of moral concern with interests and, therefore, as rightsholders. Adler's thinking leads to the opposite conclusion, denying animals their 
It is also significant and disturbing that in his latest book, Adler endorses the Thomistic view (derived from Aristotle) that ideas are basic concepts by which we understand experiences and reality as we perceive it. These basic concepts are the foundation of universal truths, which are inmutable, he insists. Ethically blind to the biased, human-centered worldview that certain basic concepts and beliefs might support, it is to be expected that if the consensus holds that other animals are inferior to us, then it must be an immutable truth.

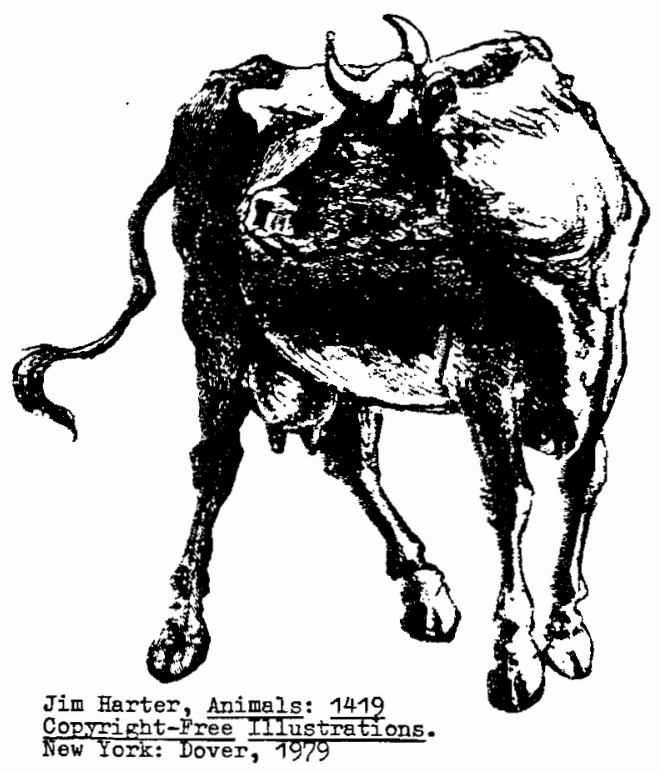

Adler's philosophy supports Wilson's biology, the fusion of which I would term "biological fascism." In an earlier book, The Difference of Man and the Difference It Makes, Adler argues that if there is a significant difference in kind, rather than in degree, between humans and animals (which has not yet been proven or unambiguously ayreed upon), then our not giving animals equal and fair consideration is ethically tenable. He notes that

[Hence] a single all-embracing continuum in nature need not exclude all differences. It allows for differences in degree and for superficial differences in kind. It excludes only radical differences in kind; for, if such exist, there is an underlying discontinuity in nature. Nor does a hierarchy of forms in nature (involving, as it does, radical differences in kind)
But even if humans, with their oognitive, linguistic and technological abilities represent a discontinuity in Nature, and differ in kind rather than in degree from animals as Adler proposes (and one may wonder about his motives for doing so), we do know that in terins of sentience, the capacity to feel and to suffer, that animals do not differ significantly from us in kind. Adler focuses his argunent on differences in sapience, which reflects the basically rational materialism of his Aristotelean, human-centered philosophy. By ignoring animal sentience, as well as recognition of their interests, he condones their exploitation on the basis of our apparently superior intellect. Adler justifies differential treatment by concluding that animals are neither rational nor moral.

The differences in kind between humans and animals are deeply entrenched in religious and philosophical beliefs (not universal, immutable truths) that humans and humans alone are made in God's image, that humans are a special creation, that only humans have immortal souls. Since the only proven difference is in our intellective, technological, and linguistic abilities, these differences, when weighed against the many similarities that we share anatomically, physiologically, biochenically, and emotionally with animals are insufficient to justify on moral grounds our calling animals mere "things" and treating them accordingly. It is simply a question of pure expediency, since I believe that there are no morally relevant differences between us and animals to permit us to exploit them as "things," purely as a means to satisfy human ends.

Darwin must have understood this dilemma, for he wrote "We are not superior" on his hand as a daily reminder.[2] That we are part of the one life and of a unified field shatters the notion of biological, evolutionary, and other hierarchies that are constructs derived not from universal and immutable truths but from our own self-centered, superior, and dominionistic attitude toward animals and the rest of God's creation.

In addition to the potentially negative bio-political implications of the above biological and philosophical views, there is a theological view, gaining popularity amongst scientists and humanists alike, that could 
lead to a widespread acceptance of the extinction of the animal kingdom as being as natural and inevitable as evolution itself.

Jesuit scientist and renowned theologian Pierre Teilhard de Chardin speaks of the "hominisation" of Earth. In other words, the world of Nature and the animal kingdom are taken over by Homo sapiens and transformed (by what he calls "techno-involution," i.e., via scientific-technological innovations). this he considered a natural consequence of the mutation in consciousness (reflective awareness) that makes us the special creation that we are.

In his book Man's Place in Nature, he accepts the industrialization of Nature as natural and inevitable:

We must realize that the continually greater industrialisation of the earth is simply the human-collective form of a universal process of vitalisation which, in this as in all other cases, can only lead, if we know the right way in which to approach it, to interiorisation and freedom.

His lack of critical analysis of the adverse consequences of the industrialization of earth, and of articulating "the right way in which to approach it," would surely be forthcoming today if he had lived and extended his philosophy in the light of today's environmental awareness. His faith in human progress as being ultimately self-correcting and stabilizing though foresight and choice may be an optimist's dream. His vision was not grounded in the reality of human destructiveness of the biosphere, for he saw the destruction of stable lands as the one serious threat to human progress which would likely be temporary and corrected by technological innovation. The spiritual and economic consequences of destroying Nature or of transforming the biosphere into an industrial system for our exclusive human use are not considered.

Teilhard de Chardin has been rightly criticized by many philosophers, conservationists, and others for not incorporating concern for the biosphere as a living system and concern for species other than his own. I greatly respect his work, however, and join others in acknowledging that he has helped break Christianity from the salvafic and hierarchical cosmology of an omipotent and anthropomorphic divinity. Indeed, he emphasized the creative, rather than salvafic, and while his mysticism was ultimately anthropocentric, his concept of divinity was closer to Whitehead's process thinking (and to spinoza's and Einstein's concept of divinity) than to the church of Rone's anthropomorphic view of God. Hence his works were suppressed by the Catholic authority of Papal decree for many years. (He was also challenging the church's patriarchal structure and entire cosmology.)

Teilhard stopped short of pantheism when he saw "Christo-genesis"--the spiritual awakening of Christ-consciousness-mas the final point in human evolution (as Homo sapiens). And his view was ultimately hierarchical, since he put people at the top of the evolutionary process.

Pantheism may then be the next religious perspective, but there may soon be nothing left of Nature to revere, if we continue to neglect and destroy the biosphere. Had Teilhard realized how critical the state of the biosphere already was when he was elaborating his cosmology (but few people were aware in the 1950's and early 1960's) and had he not such a naive faith in scientific and technological progress (as most people had in the relief and optimism in those two post-world War II decades), then he might not have excluded concern for Nature and the rest of creation. He did not see how "techno-involution"--scientific and technological "progress"--could destroy the biosphere. He saw it as the interface between the biosphere and the evolving "noosphere" (which is difficult to define simply but might be envisioned as a matrix of human consciousness, cormunication, power, and control that envelops the biosphere). Teilhard would agree that without a biosphere, there can be no noosphere and that a destructive technology would destroy both. Father Thomas Berry, of the Riverdale Center for Religious Studies, [3] has written several treatises to help put Teilhardianism into its proper contermorary setting.

Scientists and others who are attracted to Teilhard's cosmology have found it helpful, I believe, in alleviating their consciences over the annihilation of the biosphere and the present holocaust of the animal kingdom. All this is rationalized as 


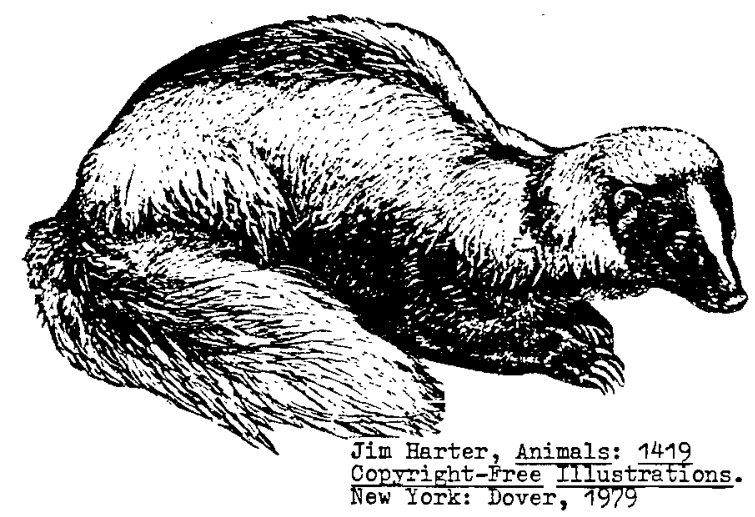

being a natural consequence of evolution-hominisation-so it doesn't matter. From this perspective, to worry about saving wolves and snow leopards is as silly today as it would have been stupid for some sentimental aliens to have saved the dinosaurs from extinction. (And had they done so, then we humans would not exist!) Their extinction is in the natural scheme. But since Teilhard never discussed the threatened status of the biosphere and the animal kingdom and its ethical and evolutionary implications, it is hardly right to conclude that his philosophy accepts, or considers, natural the destruction of Nature--the biosphere. (And under "destruction" I include loss of species, genetic diversity, habitats, ecosystems, and resources and poisoning of the entire planetary ecosystem.)

Because of his faith in evolution/God, he did not doubt that only good would arise from the transformation of the biosphere by technology and homonisation. He died too soon, but as I said, he did at least turn the church's attention away from its emphasis on world-negating salvation, toward recognition of the divine mystery that evolutionary biology reveals. A world-affirming emphasis upon the creative process rather than upon salvation is now being encouraged by Father Berry and others. In essence, this is a returin to Nature, not to pantheism, but at least toward a reverence for the Earth and God's creations.

In conclusion, I have endeavored to demonstrate, by selecting some of the ideas of contemporary thinkers in the fields of biology, philosophy, and theology, how these disciplines can be used to alienate people from animals and Nature. This alienation process, whereby people are led to believe that they are superior to animals and that there is no moral or ethical issue in the wholesale exploitation of animals and nature,

is the bio-politics of contemporary science, philosophy, and theology whose worldview is self-serving and anthropocentric--and thus lacking in scholarly objectivity and ethical sensibility. Educators, scientists, philosophers, and others need to be aware of the subtle and insidious ramifications of the worldview espoused by those whose attitude toward animals and Nature is neither democratic nor egalitarian. Rather, it can lead to the bio-politics of fascism and imperialism under the guise of academia's infallible wisdom and scholarly facade of scientific objectivity and truthfulness.

\section{Notes}

1. The Book of Lists (New York: William and Morrow).

2. James Malcolm, personal communication.

3. 5801 Palisade Avenue, Bronx, New York 10471 .

\section{ANIMALS. Do they matter?}

An exciting new awareness is unfolding about our relationship with animals and the rest of the natural world. Read about it in THE ANIMALS' AGENDA.

\section{THE ANIMALS' AGENDA gives} you news, views and articies about animal rights, welfare and protection, and about the people who are making animal rights one of the major issues of the $" 80)^{\prime} \mathrm{s}$ A WHOLE MOVEMENT IN ONE MAGAZINE.

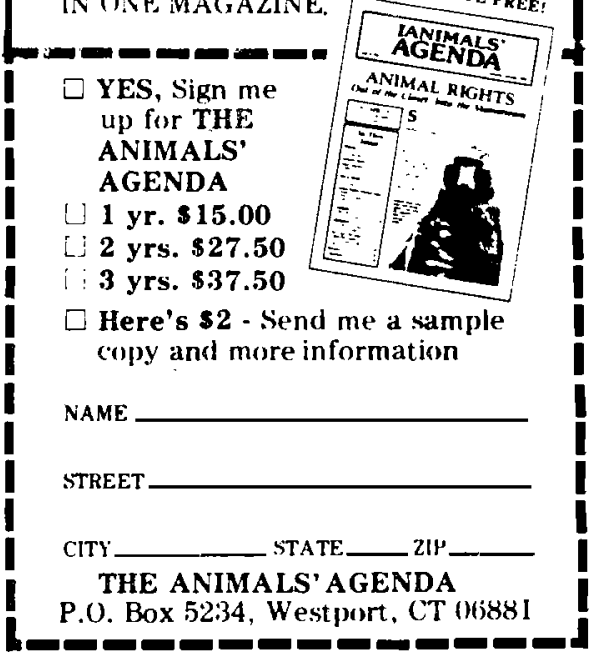

